\title{
Impact of Use Frequency of a Mobile Diabetes Management App on Blood Glucose Control: Evaluation Study
}

Josep Vehi ${ }^{1,2}$, PhD; Jordi Regincós Isern ${ }^{1}, \mathrm{PhD}$; Adrià Parcerisas ${ }^{1}, \mathrm{MSc}$; Remei Calm ${ }^{1}, \mathrm{PhD}$; Ivan Contreras ${ }^{1}, \mathrm{PhD}$

${ }^{1}$ Institut d'Informatica i Aplicacions, Universitat de Girona, Girona, Spain

${ }^{2}$ Centro de Investigación Biomédica en Red de Diabetes y Enfermedades Metabólicas Asociadas, Girona, Spain

Corresponding Author:

Josep Vehi, PhD

Institut d'Informatica i Aplicacions

Universitat de Girona

Campus Montilivi, Edifici P4

Girona, 17003

Spain

Phone: 34620131826

Email: josep.vehi@gmail.com

\section{Abstract}

Background: Technology has long been used to carry out self-management as well as to improve adherence to treatment in people with diabetes. However, most technology-based apps do not meet the basic requirements for engaging patients.

Objective: This study aimed to evaluate the effect of use frequency of a diabetes management app on glycemic control.

Methods: Overall, 2 analyses were performed. The first consisted of an examination of the reduction of blood glucose (BG) mean, using a randomly selected group of 211 users of the SocialDiabetes app (SDA). BG levels at baseline, month 3, and month 6 were calculated using the intercept of a regression model based on data from months 1,4 , and 7 , respectively. In the second analysis, the impact of low and high BG risk was examined. A total of 2692 users logging SDA $\geq 5$ days/month for $\geq 6$ months were analyzed. The highest quartile regarding low blood glucose index (LBGI) and high blood glucose index (HBGI) at baseline (t1) was selected ( $\mathrm{n}=74$ for group A; $\mathrm{n}=440$ for group B). Changes in HBGI and LBGI at month 6 (t2) were analyzed.

Results: For analysis 1, baseline BG results for type 1 diabetes mellitus (T1DM) groups A and B were 213.61 (SD 31.57) mg/dL and 206.43 (SD 18.65) $\mathrm{mg} / \mathrm{dL}$, respectively, which decreased at month 6 to 175.15 (SD 37.88) $\mathrm{mg} / \mathrm{dL}$ and 180.6 (SD 40.47) $\mathrm{mg} / \mathrm{dL}$, respectively. For type 2 diabetes mellitus (T2DM), baseline BG was 218.77 (SD 40.18) mg/dL and 232.55 (SD 46.78) $\mathrm{mg} / \mathrm{dL}$, respectively, which decreased at month 6 to 160.51 (SD 39.32) $\mathrm{mg} / \mathrm{dL}$ and 173.14 (SD 52.81) $\mathrm{mg} / \mathrm{dL}$ for groups A and $\mathrm{B}$, respectively. This represents a reduction of estimated $\mathrm{A}_{1 \mathrm{c}}\left(\mathrm{eA}_{1 \mathrm{c}}\right)$ of approximately $1.3 \%(P<.001)$ and $0.9 \%(P=.001)$ for T1DM groups A and B, respectively, and 2\% $(P<.001)$ for both A and B T2DM groups, respectively. For analysis 2, T1DM baseline LBGI values for groups A and B were 5.2 (SD 3.9) and 4.4 (SD 2.3), respectively, which decreased at t2 to 3.4 (SD 3.3) and 3.4 (SD 1.9), respectively; this was a reduction of $34.6 \%(P=.005)$ and $22.7 \%(P=.02)$, respectively. Baseline HBGI values for groups A and B were 12.6 (SD 4.3) and 10.6 (SD 4.03), respectively, which decreased at t2 to 9.0 (SD 6.5) and 8.6 (SD 4.7), respectively; this was a reduction of $30 \%(P=.001)$ and $22 \%(P=.003)$, respectively.

Conclusions: A significant reduction in BG was found in all groups, independent of the use frequency of the app. Better outcomes were found for T2DM patients. A significant reduction in LBGI and HBGI was found in all groups, regardless of the use frequency of the app. LBGI and HBGI indices of both groups tend to have similar values after 6 months of app use.

(JMIR Mhealth Uhealth 2019;7(3):e11933) doi: $\underline{10.2196 / 11933}$

\section{KEYWORDS}

diabetes mellitus; mHealth; self-management; blood glucose self-monitoring; evaluation studies 


\section{Introduction}

\section{Background}

Diabetes mellitus (DM) is a chronic disease with a major impact on morbidity and mortality as well as socioeconomics [1]. This impact is because of its high prevalence and incidence as well as the associated acute and chronic complications, which are caused by poor glucose control [1]. Therefore, self-management of blood glucose (BG) is the standard of care for people with diabetes [2]. On the basis of previous studies, it has been found that for those with type 2 diabetes (T2DM) BG can be maintained through physical activity, healthy diet, and weight loss [3-5]. For people with type 1 diabetes (T1DM), it is more difficult to control through diet and exercise. Despite this, current studies suggest that those with T1DM and T2DM do not adhere to these recommendations [4,6]. Mobile health (mHealth) apps could be a solution to promote adherence to physical activity and weight reduction regimens. However, current apps require intensive one-on-one or group lifestyle coaching [7].

Technology has long been used in self-management and to improve treatment adherence in people with diabetes [8-10]. Systems based on telephone coaching, short message service support, or telemedicine have proven effective in increasing management adherence and, consequently, improving glycemic control $[9,10]$. Currently, the global implementation of mobile phones has fostered the development of apps for diabetes management, which have become primary tools for decision support and disease management for both people with diabetes and health care providers [11]. However, some of these apps have not been proven to work in real life, and some studies have observed that they generally do not meet the basic requirements for engaging the patient [12-14].

Retrospective studies of diabetes management apps have recently been reported, which have demonstrated a reduction in mean glucose [15-18], glycated hemoglobin $\left(\mathrm{HbA}_{1 \mathrm{c}}\right)$ levels, and the risk of hypoglycemia for patients who used an app frequently [18-20]. However, many of these studies have focused on the improvement of BG control for adherent patients rather than on the level of adherence needed to obtain this impact on glycemic control [21,22]. For this reason, other recent reviews have demonstrated that very few of these apps use this information to provide users with personalized feedback, education, or motivation [23,24].

Thus, starting from the premise that an app that promotes patient education toward their disease and assists in increasing the efficacy of their treatment and self-regulation is needed, we have performed an analysis on a current mHealth app to devise a methodology to make apps more effective for this purpose. The primary objective of this study was to evaluate the effect of the use frequency of a diabetes management app on glycemic control in participants with DM. The results presented in this paper correspond to 2 retrospective analyses. The first analysis consisted of examining the effect of the use frequency of a diabetes management app on the reduction of estimated $\mathrm{HbA}_{1 \mathrm{c}}$ levels. The goal of the second study was to examine the app's impact on the low blood glucose index (LBGI) and high blood glucose index (HBGI).

\section{SocialDiabetes System}

SocialDiabetes is an independent digital health care platform for diabetes management, created by people with diabetes to transform the everyday life of patients by unlocking the potential of data-driven innovation and community development. The platform is complete with a mobile app and a desktop solution that empowers diabetes patients to actively engage in their own care. A global vision of the platform and its characteristics are shown in Figure 1.

Using the SocialDiabetes app (SDA), patients can sync their BG data from their meter to their phone and add any other relevant information in real time (ie, exercise, food, and lifestyle). Professional practitioner care teams employed by the app are connected to the patients through the SDA care Web platform and can remotely monitor and track their progress. Data are accessible to both patients and health care providers. In the near future, SDA will incorporate a community platform. Its intention is to bring the possibility of facilitating communication not only between the patient and physician but also between all patients with diabetes with similar characteristics. In this manner, each patient will be able to explain their experience to others.

Some basic tools such as remote monitoring of patients, $\mathrm{HbA}_{1 \mathrm{c}}$ estimation, carbohydrates calculators, alerts, and reminders characterize the platform. As they encourage patient personalization, the app also provides personalized insulin dose recommendations, connection with health care professionals, meal planning, exercise coaching and charts, and insights about the parameters and statistics of every patient.

The objective of this study was to demonstrate by means of 2 analyses on 2 independent indicators of glycemic control that the impact of a diabetes management app on glycemic control is more related to its monthly users' usage in a consistent manner rather than daily, weekly or monthly high-frequency use. When we talk about consistency, we are referring to a habit that is followed on a regular basis and over a long period. So, the use of the app is a part of his/her diabetes management routine. In other words, the frequency of use necessary to generate consistency is a specific parameter for each individual. Therefore, the frequency of use is not a determinant for glycemic control as long as it is sufficient to generate a consistent use of the app. Thus, users logging into the app on a monthly basis for a long time can have an impact on glycemic control regardless of whether their frequency of use is high or low. 
Figure 1. General scheme of the SocialDiabetes integrated platform.

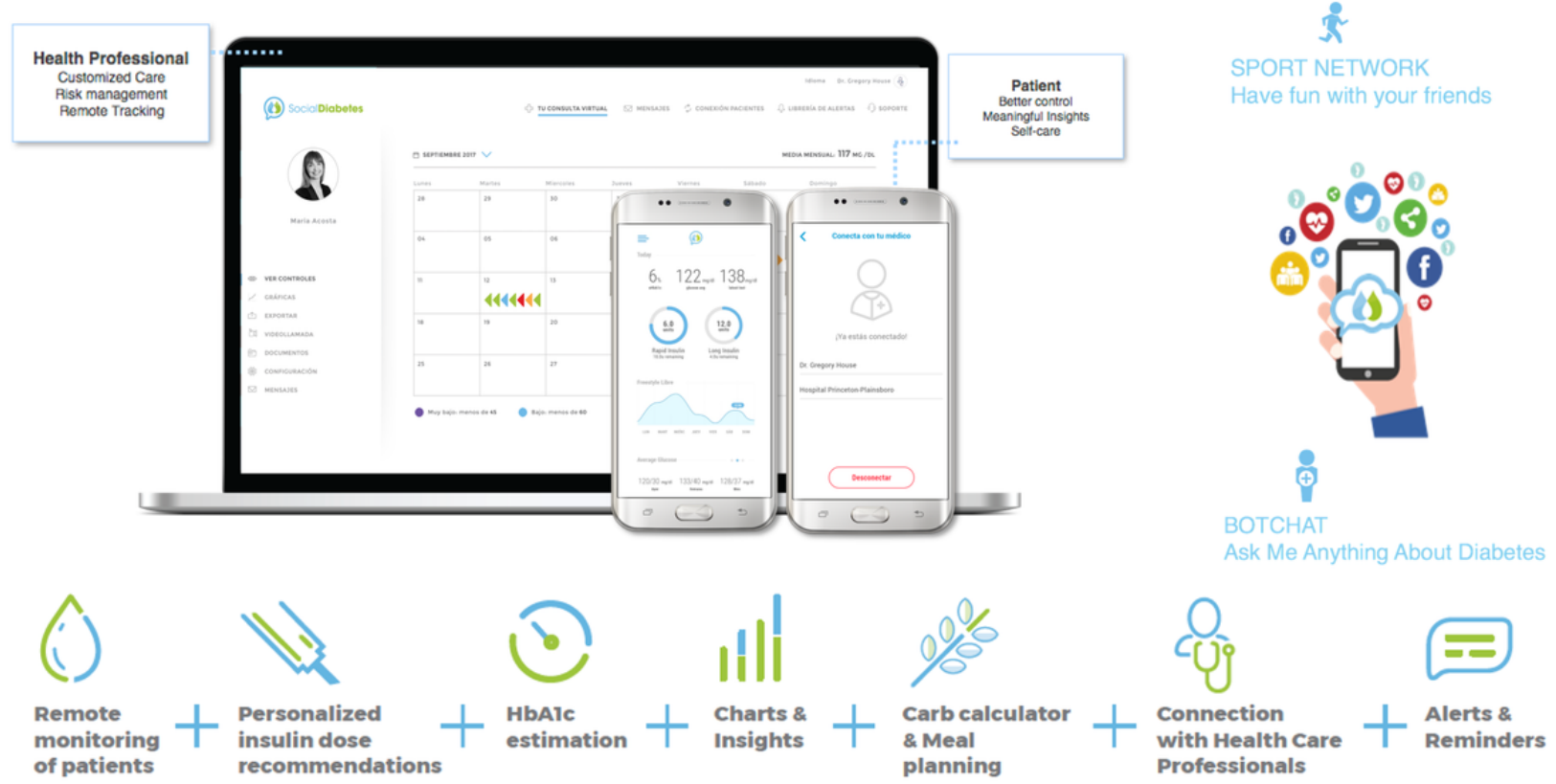

\section{Methods}

\section{Description of Study Participants}

In this study, 2 different measures for glycemic control have been conducted: the first evaluating the $\mathrm{HbA}_{1 \mathrm{c}}$ levels through the frequency of use of the app and the second examining its impact on LBGI and HBGI.

To perform the study, a subset of informed consenting users of the SDA database was first selected. The inclusion criteria were 18 years old or more, more than 1 year with diabetes, and no complications. An additional engagement inclusion criterion was applied, which consisted of an analysis of an app usage report where users who were logging in at least 5 days per month during at least 6 months (logging $\geq 5$ days/month for $\geq 6$ months) were selected. Users have been previously distinguished according to T1DM and T2DM as disease management between the two is often very different. Finally, to have an adequate sample of users and to obtain more accurate results, a different inclusion/exclusion criterion was used for each of the 2 analyses.

\section{Reduction of Estimated Glycated Hemoglobin}

A total of 211 users of the SDA were included in the analysis, among which $144(68.2 \%)$ participants had T1DM and 67 (31.8\%) had T2DM. For this analysis, a mean BG inclusion criterion was applied, where participants with mean BG levels at baseline more than or equal to $183 \mathrm{mg} / \mathrm{dL}$ (representing e $\mathrm{A}_{1 \mathrm{c}}$ $\geq 8 \%$ ) were selected.

Among the users, 19 (9\%) had a body mass index (BMI) less than $18.5,98(46.4 \%)$ had between 18.5 and $25,74(35.1 \%)$ had between 25 and 30, and $20(9.5 \%)$ had greater than 30 . Almost half of the selected users $(99 / 211)$ were diagnosed between 10 and 30 years ago, 40.3\% (85/211) was diagnosed less than 10 years ago, and the other users (27/211) were diagnosed over 30 years ago.
In addition, 144 (68.2\%) users had T1DM, of which 57.6\% $(83 / 144)$ were male and $42.4 \%(61 / 144)$ were female. The mean age of males was statistically higher than that of females, 34.8 (SD 4.22) years versus 31.93 (SD 3.14) years, respectively. Conversely, participants with T2DM constituted $31.8 \%(67 / 211)$ of the total participants, with $74.6 \%(50 / 67)$ being male and $25.4 \%(17 / 67)$ being female. In this case, the mean age of males was higher than that of females, 53.2 (SD 4.02) years for males and 49.1 (SD 4.11) years for females.

The cohort was split into 2 groups according to the intensity of app engagement: group A represents the high-engagement group (logging $\geq 15$ times/month for $\geq 6$ months) and group $B$ represents the low-engagement group (logging 5-10 times/month for $\geq 6$ months). Applying this criterion, group A represents $57 \%$ (82/144) of T1DM participants and 67\% (45/67) of participants with T2DM. The other participants for both T1DM and T2DM were included in group B, representing 43\% (62/133) of T1DM and $33 \%(22 / 45)$ of T2DM participants.

BG levels at baseline, month 3 , and month 6 were calculated using the intercept of a regression model based on data from months 1, 4, and 7, respectively. Estimated $\mathrm{HbA}_{1 \mathrm{c}}$ was calculated at baseline, month 3 , and month 6 using linear regression analysis as described in the study by Holmes et al [22]. Paired $t$ test was used to test the mean difference between baseline, month 3 , and month 6 .

\section{Reduction of Risks of Hypoglycemia and Hyperglycemia}

A total of 2692 users of the SDA were analyzed, of which 2248 $(83.5 \%)$ of the participants had T1DM and 444 (16.5\%) of the participants had T2DM. The inclusion criterion of this analysis consisted of engagement.

Among the subset selected, $161(6 \%)$ participants had a BMI less than $18.5,1146(42.6 \%)$ had between 18.5 and 25,779 (28.9\%) had between 25 and 30, and 606 (22.5\%) had greater 
than 30. More than half of them were diagnosed less than 10 years ago (1404/2692), 37.5\% (1010/2692) were diagnosed between 10 and 30 years ago, and the other users (278/2692) were diagnosed over 30 years ago.

Of the participants, 2248 (83.5\%) had T1DM, of whom 59\% $(1326 / 2248)$ were male and $41 \%(922 / 2248)$ were female. The mean age for the males was statistically higher than that of the females, 36.7 (SD 4.98) years versus 31.81 (SD 3.34) years, respectively. Conversely, participants with T2DM constituted $16.5 \%(444 / 2692)$ of the total participants, with $79.3 \%(352 / 444)$ being male and $20.7 \%$ (92/444) being female. In this case, the mean age of males was higher than that of females, 55.2 (SD 4.22) years for male and 48.7 (SD 4.41) years for females.

The cohort was split into 2 groups according to the intensity of app engagement: group A, the high-engagement group (logging $\geq 60$ times/month for $\geq 6$ months), and group $B$, the low-engagement group (logging 5-10 times/month for $\geq 6$ months). Applying this criterion, group A represents $86 \%$ of T1DM participants $(1944 / 2248)$ and $66 \%$ of participants with T2DM (292/444). The other participants for both T1DM and T2DM were included in group B, representing 14\% (304/2248) of T1DM and 34\% (152/444) of T2DM participants.

The LBGI and HBGI were calculated according to the methods described in the study by Nathan et al [25]. It is well known that these indexes correlate with the risk of having hypoglycemia and hyperglycemic events, respectively [26].

From each group, the highest quartile regarding LBGI and HBGI at baseline (t1) was selected $\left(n_{1}=486\right.$ and $n_{2}=73$ for group $A$; $\mathrm{n}_{1}=76$ and $\mathrm{n}_{2}=38$ for group $B$, where $\mathrm{n}_{1}$ and $\mathrm{n}_{2}$ refers to the number of T1DM and T2DM users respectively). Changes in HBGI and LBGI at month $6(\mathrm{t} 2)$ were analyzed. Paired $t$ test was used to compare HBGI and LBGI at baseline with those at month 6 .

\section{Results}

\section{Reduction of Estimated Glycated Hemoglobin}

Baseline BG results for T1DM groups A and B were 213.61 (SD 31.57) $\mathrm{mg} / \mathrm{dL}$ and 206.43 (SD 18.65) $\mathrm{mg} / \mathrm{dL}$, respectively, which decreased to 175.15 (SD 37.88) $\mathrm{mg} / \mathrm{dL}$ and 180.60 (SD 40.47) $\mathrm{mg} / \mathrm{dL}$ by month 6 , respectively. The mean baseline BG reduction was $18 \%(P<.001)$ and $13 \%(P=.001)$ for groups $\mathrm{A}$ and $\mathrm{B}$, respectively. For the T2DM groups, baseline BG level was 218.77 (SD 40.18) $\mathrm{mg} / \mathrm{dL}$ and 232.55 (SD 46.78) $\mathrm{mg} / \mathrm{dL}$, respectively, which decreased to 160.51 (SD 39.32) $\mathrm{mg} / \mathrm{dL}$ and 173.14 (SD 52.81) $\mathrm{mg} / \mathrm{dL}$ by month 6 for groups A and B, respectively. The mean baseline $\mathrm{BG}$ reduction was $27 \%$ $(P<.001)$ and $26 \%(P<.001)$ at month 6 for groups A and B, respectively. All statistical results are summarized in Table 1 and can be seen in Figures 2 and 3.

On the basis of $\mathrm{BG}$ reduction, this corresponds to a reduction of $\mathrm{eA}_{1 \mathrm{c}}$ of approximately $1.3 \%$ and $0.9 \%$ for T1DM groups $\mathrm{A}$ and $\mathrm{B}$, respectively, and $2 \%$ for both T2DM groups A and B, respectively, and the statistical results are enumerated in Table 2 and represented in Figures 2 and 3.

\section{Reduction of Hypoglycemia and Hyperglycemia Risk}

T1DM baseline LBGI results for groups A and B were 5.2 (SD 3.9) and 4.4 (SD 2.3), respectively, which decreased to 3.4 (SD 3.3) and 3.4 (SD 1.9) by month 6, respectively; a reduction of $39 \%(P=.005)$ and $22 \%(P=.02)$, respectively, in the mean. The baseline HBGI results for groups A and B were 12.6 (SD 4.3) and 10.6 (SD 4.03), respectively, which decreased to 9.0 (SD $6.5)$ and 8.6 (SD 4.7) by month 6 , respectively. The mean reduction in baseline HBGI was $30 \%(P=.001)$ and $22 \%$ $(P=.003)$ for groups A and $\mathrm{B}$, respectively.

For T2DM users, the baseline LBGI results for groups A and B were 1.52 (SD 1.15) and 2.62 (SD 1.76), respectively, which decreased to 1.13 (SD 1.14) and 2.12 (SD 0.96) by month 6 , respectively. The mean reduction in baseline LBGI was $25 \%$ $(P=.01)$ and $19 \%(P=.03)$ for groups $\mathrm{A}$ and $\mathrm{B}$, respectively. For HBGI, the baseline results for groups A and B were 9.71 (SD 4.63) and 9.70 (SD 4.34), which decreased to 4.27 (SD 4.26) and 5.57 (SD 2.61) by month 6, respectively. The mean reduction in baseline HBGI was $56 \%(P<.001)$ and $44 \%$ $(P<.001)$ for groups A and $\mathrm{B}$, respectively.

Table 1. The evolution of blood glucose in type 1 diabetes and type 2 diabetes users.

\begin{tabular}{lllll}
\hline Type and engagement & $\mathrm{N}$ & $\begin{array}{l}\text { Blood glucose } \\
\text { Baseline, mean (SD) }\end{array}$ & Month 3, mean (SD) & Month 6, mean (SD) \\
\hline $\begin{array}{l}\text { Type 1 diabetes } \\
\text { High }\end{array}$ & 82 & $213.61(31.57)$ & $177.45(37.31)$ & $175.15(37.88)$ \\
$\quad$ Low & 62 & $206.42(18.65)$ & $179.46(30.99)$ & $180.60(31.57)$ \\
Type 2 diabetes & & & $171.99(44.77)$ & $160.51(39.32)$ \\
$\quad$ High & 45 & $218.78(40.18)$ & $162.52(41.65)$ & $173.14(49.08)$ \\
$\quad$ Low & 22 & $232.55(47.78)$ & & \\
\hline
\end{tabular}


Figure 2. Timeline evolution of estimated blood glucose (left) and estimated glycated hemoglobin (right) for users with type 1 diabetes mellitus.
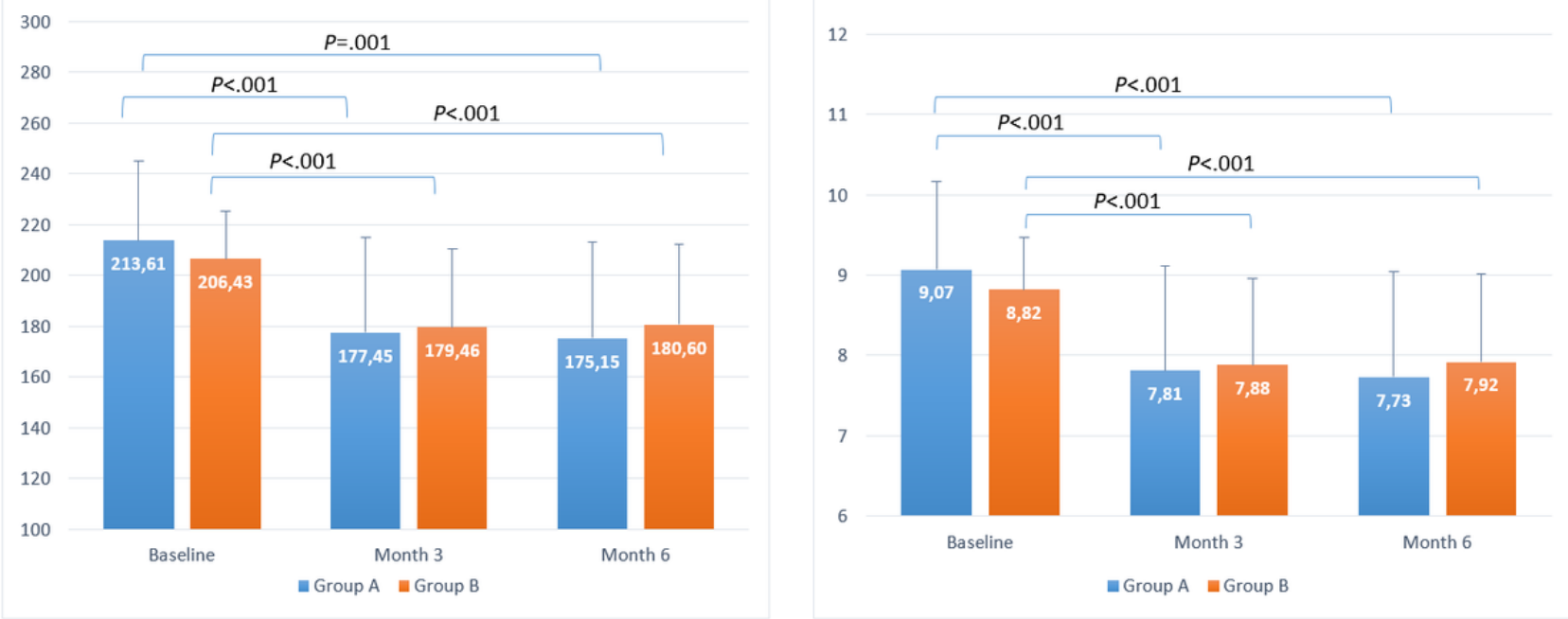

Figure 3. Timeline evolution of estimated blood glucose (left) and estimated glycated hemoglobin (right) for users with type 2 diabetes mellitus.
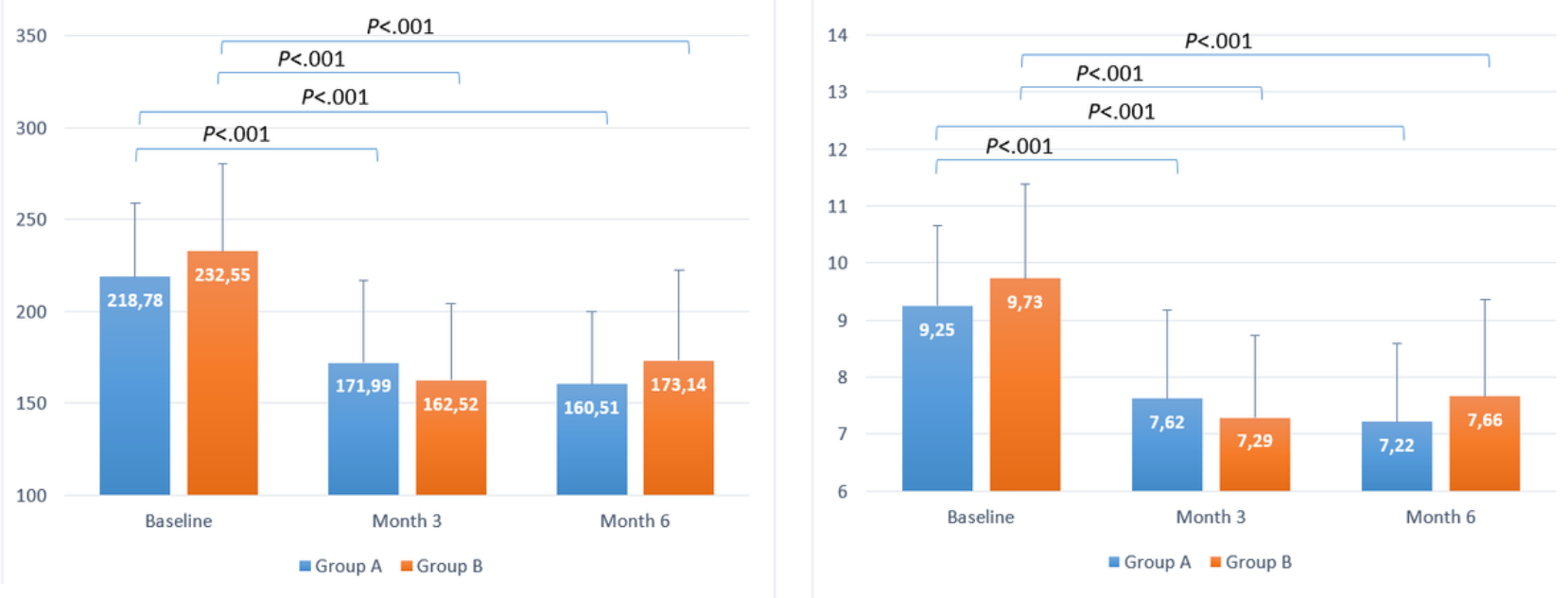

Table 2. The evolution of estimated glycated hemoglobin in type 1 diabetes and type 2 diabetes users.

\begin{tabular}{|c|c|c|c|c|}
\hline \multirow[t]{2}{*}{ Type and engagement } & \multirow[t]{2}{*}{$\mathrm{N}$} & \multicolumn{3}{|l|}{ Glycated hemoglobin } \\
\hline & & Baseline, mean (SD) & Month 3, mean (SD) & Month 6, mean (SD) \\
\hline \multicolumn{5}{|l|}{ Type 1 diabetes } \\
\hline High & 82 & $9.07(1.10)$ & $7.81(1.30)$ & $7.73(1.32)$ \\
\hline Low & 62 & $8.82(0.65)$ & $7.88(1.08)$ & $7.92(1.10)$ \\
\hline \multicolumn{5}{|l|}{ Type 2 diabetes } \\
\hline High & 45 & $9.25(1.40)$ & $7.62(1.56)$ & $7.22(1.37)$ \\
\hline Low & 22 & $9.73(1.66)$ & $7.29(1.45)$ & $7.66(1.71)$ \\
\hline
\end{tabular}

For T1DM users, the baseline LBGI results for groups A and B were 4.72 (SD 1.93) and 4.4 (SD 1.34), respectively, and decreased at $\mathrm{t} 2$ to 2.92 (SD 2.20) and 3.45 (SD 1), respectively; this was a reduction of $39 \%(P=.005)$ and $22 \%(P=.02)$, respectively, in the mean.

Baseline HBGI results for groups A and B were 12.72 (SD 3.79) and 11.07 (SD 3.07), respectively, and decreased at t2 to 8.92 (SD 5.35) and 8.61 (SD 3.86), respectively; this was a reduction of $30 \%(P=.002)$ and $22 \%(P=.004)$, respectively, in the mean. All statistical results are summarized in Table 3 and shown in Figures 4 and 5. 
Table 3. The evolution of both low blood glucose index and high blood glucose index for type 1 diabetes and type 2 diabetes users.

\begin{tabular}{|c|c|c|c|c|c|}
\hline \multirow[t]{2}{*}{ Type and engagement } & \multirow[t]{2}{*}{$\mathrm{N}$} & \multicolumn{2}{|c|}{ Low blood glucose index } & \multicolumn{2}{|c|}{ High blood glucose index } \\
\hline & & Baseline, mean (SD) & Month 6, mean (SD) & Baseline, mean (SD) & Month 6, mean (SD) \\
\hline \multicolumn{6}{|l|}{ Type 1 diabetes } \\
\hline High & 486 & $4.44(1.34)$ & $3.45(1.00)$ & $9.73(1.66)$ & $8.61(3.86)$ \\
\hline Low & 76 & $4.72(1.93)$ & $2.92(2.20)$ & $12.72(3.79)$ & $8.92(5.35)$ \\
\hline High & 73 & $2.62(1.76)$ & $2.12(0.96)$ & $9.70(4.34)$ & $5.57(2.61)$ \\
\hline Low & 38 & $1.52(1.15)$ & $1.13(1.14)$ & $9.71(4.63)$ & $4.27(4.26)$ \\
\hline
\end{tabular}

Figure 4. Timeline evolution of low blood glucose index (left) and high blood glucose index (right) for users with type 1 diabetes mellitus.
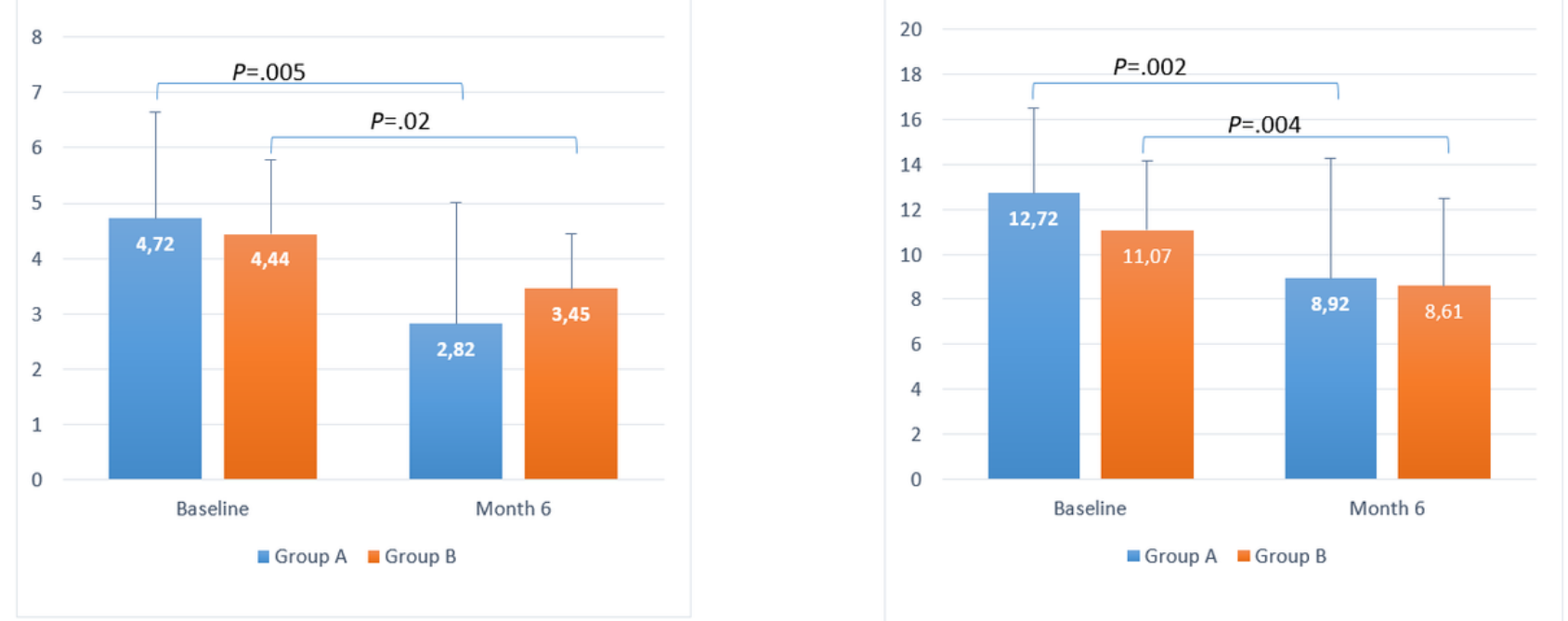

Figure 5. Timeline evolution of low blood glucose index (left) and high blood glucose index (right) for users with type 2 diabetes mellitus.

\section{Discussion}

\section{Principal Findings}

Significant reductions in BG levels were found in all groups, independent of the use frequency of the app. We also found better outcomes for participants with T2DM.

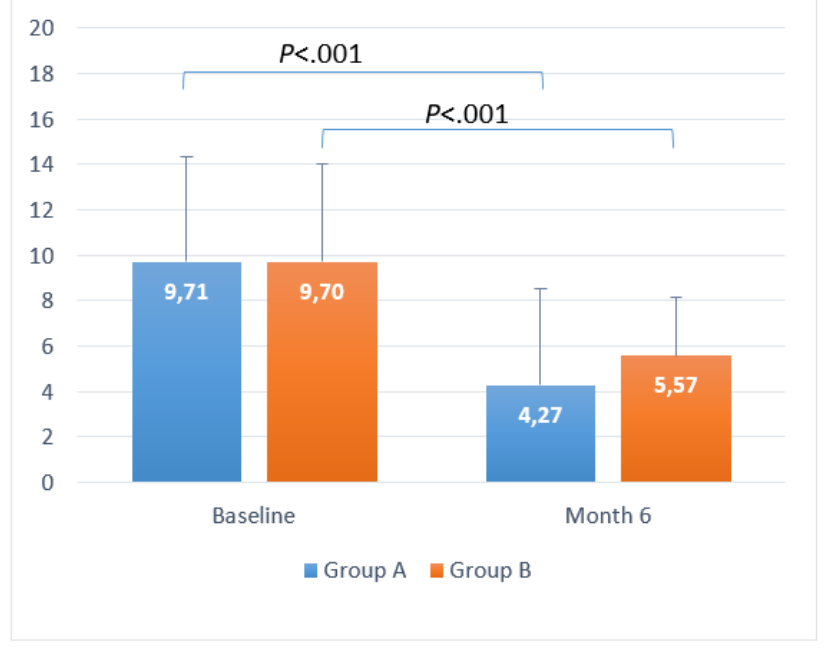

Significant reductions in LBGI and HBGI were found in all groups, regardless of the use frequency of the app. LBGI and HBGI of both groups tended to have similar values after using the app for 6 months.

We also found a slight increase in the estimated $\mathrm{HbA}_{1 \mathrm{c}}$ between 3 and 6 months. However, as $P$ value shows in all cases, this increment is not significant. 
The positive change in both $\mathrm{HbA}_{1 \mathrm{c}}$ and risk indices for hypoglycemia and hyperglycemia, regardless of the frequency of use of the app by users, demonstrates the initial hypothesis, arguing that frequency of app use is not as important as the consistency and continuity of use. Thus, our hypothesis states that consistent and continuous app use results in an improvement of glycemic control, regardless of use frequency.

SDA has been shown to help patients by improving disease management, even during infrequent app use. Our guess is that this is because of the patient's ability to learn disease management skills through the app, which aids in decision making and enables users to recognize specific situations, even without constant support from the app. Therefore, the higher-frequency use does not translate directly into improved performance or benefits, but rather an optimum between frequency and consistency is required.

\section{Limitations}

In this study, we considered the limited number of participants and the access difficulty to the SDA database as study limitations. The main problem was the need of a project manager or an expert from the company to solve problems associated with the database to facilitate data reorganization. Therefore, there was a lack of communication between the app entity and our research group, which caused access to the SDA database to be difficult. In addition, because of this lack of reorganization, a significant amount of data was lost. For this reason, the number of participants was less than expected.

In more detail, 11,542 users were analyzed from more than 12,000 registered users in the SDA database with the accepted ethical consent. The problem was based on an error in the link that allowed users to save their controls. Sometimes, the link failed, and consequently, the controls were lost. A huge number of users were not able to register their own controls and could not be evaluated. Despite this, the number of users to be evaluated was enough because more than $95 \%$ of users could be evaluated.

The patients that have been analyzed in this study have been taken directly from the database and analyzed retrospectively. So, we do not have complete data on other sources of support/care/teaching that they may have had. However, in surveys conducted by the company in patient samples, no differences were detected between the different groups of patients.

\section{Conclusions}

SDA is the first app that demonstrates that the more use, the better belief is not always optimal. In the case of SDA, the results are similar for both cases of lower-frequency and higher-frequency users. Using SDA may favorably impact glycemic control. Moreover, it is one of the few apps that may improve self-management for both T1DM and T2DM patients. As previously stated, the patient can learn how to manage his or her disease with this app, which increases patient empowerment and improves self-management, even for a very low use frequency.

Hence, we propose an innovative app, SocialDiabetes, as a self-management platform for people with any type of diabetes that aims to help people with diabetes live healthier, more comfortable lives. Through the activity of the patient, SDA provides tools, guidelines, and advice to the patient so that he/she can improve his/her management, knowledge, and self-care motivation toward his/her disease.

Pending studies to be carried out in the future include the study of the user's experience and how this experience can improve patient empowerment. The improvement in the quality of life should also be studied.

\section{Acknowledgments}

This study was partially supported by the Spanish Ministry of Science and Innovation under grant DPI2016-78831-C2-2-R and by the Autonomous Government of Catalonia under grant 2017 SGR 1551.

\section{Conflicts of Interest}

JV has worked in SocialDiabetes as the Chief Researcher Officer and also received research support. The terms of this arrangement have been reviewed and approved by the University of Girona in accordance with its policy on objectivity in research.

\section{References}

1. Pons JMV, Agència de Qualitat i Avaluació Sanitàries de Catalunya. Generalitat de Catalunya. 2016. [Flash FreeStyle Libre ${ }^{\circledR}$ device for the monitoring of glycemia] URL: http://aquas.gencat.cat/web/.content/minisite/aquas/publicacions/ 2016/documents/Flash freeStyleLibre glucemia aquas2016.pdf [accessed 2019-02-28] [WebCite Cache ID 76WYr9zNv]

2. Ish-Shalom M, Wainstein J, Raz I, Mosenzon O. Improvement in glucose control in difficult-to-control patients with diabetes using a novel flash glucose monitoring device. J Diabetes Sci Technol 2016 Dec;10(6):1412-1413 [FREE Full text] [doi: 10.1177/1932296816653412] [Medline: 27277660]

3. Balk EM, Earley A, Raman G, Avendano EA, Pittas AG, Remington PL. Combined diet and physical activity promotion programs to prevent type 2 diabetes among persons at increased risk: a systematic review for the Community Preventive Services Task Force. Ann Intern Med 2015 Sep 15;163(6):437-451 [FREE Full text] [doi: 10.7326/M15-0452] [Medline: $\underline{26167912]}$ 
4. Aune D, Norat T, Leitzmann M, Tonstad S, Vatten LJ. Physical activity and the risk of type 2 diabetes: a systematic review and dose-response meta-analysis. Eur J Epidemiol 2015 Jul;30(7):529-542. [doi: 10.1007/s10654-015-0056-z] [Medline: 26092138]

5. Muralidharan S, Mohan V, Anjana RM, Jena S, Tandon N, Allender S, et al. Mobile health technology (mDiab) for the prevention of type 2 diabetes: protocol for a randomized controlled trial. JMIR Res Protoc 2017 Dec 12;6(12):e242 [FREE Full text] [doi: 10.2196/resprot.8644] [Medline: 29233806]

6. Colberg SR, Laan R, Dassau E, Kerr D. Physical activity and type 1 diabetes: time for a rewire? J Diabetes Sci Technol 2015 May;9(3):609-618 [FREE Full text] [doi: 10.1177/1932296814566231] [Medline: 25568144]

7. Everett E, Kane B, Yoo A, Dobs A, Mathioudakis N. A novel approach for fully automated, personalized health coaching for adults with prediabetes: pilot clinical trial. J Med Internet Res 2018 Feb 27;20(2):e72 [FREE Full text] [doi: 10.2196/jmir.9723] [Medline: 29487046]

8. Whitehead L, Seaton P. The effectiveness of self-management mobile phone and tablet apps in long-term condition management: a systematic review. J Med Internet Res 2016;18(5):e97 [FREE Full text] [doi: 10.2196/jmir.4883] [Medline: 27185295]

9. Reach G. Can technology improve adherence to long-term therapies? J Diabetes Sci Technol 2009 May 1;3(3):492-499 [FREE Full text] [doi: 10.1177/193229680900300313] [Medline: 20144287]

10. Greenwood DA, Gee PM, Fatkin KJ, Peeples M. A systematic review of reviews evaluating technology-enabled diabetes self-management education and support. J Diabetes Sci Technol 2017 Sep;11(5):1015-1027. [doi: 10.1177/1932296817713506] [Medline: 28560898]

11. Kaufman N. Using health information technology to prevent and treat diabetes. Diabetes Technol Ther 2013 Feb;15(Suppl 1):S60-S74. [doi: 10.1089/dia.2013.1507] [Medline: 23441709]

12. Wu Y, Yao X, Vespasiani G, Nicolucci A, Dong Y, Kwong J, et al. Mobile app-based interventions to support diabetes self-management: a systematic review of randomized controlled trials to identify functions associated with glycemic efficacy. JMIR Mhealth Uhealth 2017 Mar 14;5(3):e35 [FREE Full text] [doi: 10.2196/mhealth.6522] [Medline: 28292740]

13. Kitsiou S, Paré G, Jaana M, Gerber B. Effectiveness of mHealth interventions for patients with diabetes: an overview of systematic reviews. PLoS One 2017;12(3):e0173160 [FREE Full text] [doi: 10.1371/journal.pone.0173160] [Medline: $\underline{28249025]}$

14. Hamine S, Gerth-Guyette E, Faulx D, Green BB, Ginsburg AS. Impact of mHealth chronic disease management on treatment adherence and patient outcomes: a systematic review. J Med Internet Res 2015;17(2):e52 [FREE Full text] [doi: 10.2196/jmir.3951] [Medline: 25803266]

15. Wilhide IC, Peeples MM, Anthony KR. Evidence-based mHealth chronic disease mobile app intervention design: development of a framework. JMIR Res Protoc 2016;5(1):e25 [FREE Full text] [doi: 10.2196/resprot.4838] [Medline: 26883135]

16. Hompesch M, Kalcher K, Debong F, Morrow L. ProSciento. 2017. Significant Improvement of Blood Glucose Control in a High Risk Population of Type 1 Diabetes Using a Mobile Health App - A Retrospective Observational Study URL: http:/ /tinyurl.com/y5u2m95o [accessed 2019-02-28] [WebCite Cache ID 76WaIGwFv]

17. Hompesch M, Hergesheimer L, Kalcher K, Boubela L, Debong F. Retrospective analysis of Impact on SMBG and Glycemic Control of Mobile Health (mHealth)-Application for Diabetes Management [Abstract, Poster]. 2016 Presented at: 16th Diabetes Technology Meeting; November 10-12, 2016; Bethesda, Maryland. [doi: 10.1177/1932296817696371]

18. Hompesch M, Kalcher K, Debong F. mySugr.com. 2017. High Risk Population Using Mobile Logging App Shows Significant Reduction in LBGI URL: https://assets.mysugr.com/website/mysugr.com-wordpress/uploads/2017/06/ada-2017-poster.pdf [accessed 2019-02-28] [WebCite Cache ID 76WanYkuh]

19. Goyal S, Nunn CA, Rotondi M, Couperthwaite AB, Reiser S, Simone A, et al. A mobile app for the self-management of type 1 diabetes among adolescents: a randomized controlled trial. JMIR Mhealth Uhealth 2017 Jun 19;5(6):e82 [FREE Full text] [doi: 10.2196/mhealth.7336] [Medline: 28630037]

20. Pérez-Gandía C, García-Sáez G, Subías D, Rodríguez-Herrero A, Gómez EJ, Rigla M, et al. Decision support in diabetes care: the challenge of supporting patients in their daily living using a mobile glucose predictor. J Diabetes Sci Technol 2018 Dec;12(2):243-250. [doi: 10.1177/1932296818761457] [Medline: 29493361]

21. Náfrádi L, Nakamoto K, Schulz PJ. Is patient empowerment the key to promote adherence? A systematic review of the relationship between self-efficacy, health locus of control and medication adherence. PLoS One 2017;12(10):e0186458 [FREE Full text] [doi: 10.1371/journal.pone.0186458] [Medline: 29040335]

22. Holmes EA, Hughes DA, Morrison VL. Predicting adherence to medications using health psychology theories: a systematic review of 20 years of empirical research. Value Health 2014 Dec;17(8):863-876 [FREE Full text] [doi: 10.1016/j.jval.2014.08.2671] [Medline: 25498782]

23. Holtz BE, Murray KM, Hershey DD, Dunneback JK, Cotten SR, Holmstrom AJ, et al. Developing a patient-centered mHealth app: a tool for adolescents with type 1 diabetes and their parents. JMIR Mhealth Uhealth 2017 Apr 19;5(4):e53 [FREE Full text] [doi: 10.2196/mhealth.6654] [Medline: 28428167]

24. Osborn CY, van Ginkel JR, Marrero DG, Rodbard D, Huddleston B, Dachis J. One Drop | Mobile on iPhone and Apple Watch: an evaluation of HbA1c improvement associated with tracking self-care. JMIR Mhealth Uhealth 2017 Nov 29;5(11):e179 [FREE Full text] [doi: 10.2196/mhealth.8781] [Medline: 29187344] 
25. Nathan DM, Kuenen J, Borg R, Zheng H, Schoenfeld D, Heine RJ, A1c-Derived Average Glucose Study Group. Translating the A1C assay into estimated average glucose values. Diabetes Care 2008 Aug;31(8):1473-1478 [FREE Full text] [doi: 10.2337/dc08-0545] [Medline: 18540046]

26. Kovatchev BP, Straume M, Cox DJ, Farhy LS. Risk analysis of blood glucose data: a quantitative approach to optimizing the control of insulin dependent diabetes. Journal of Theoretical Medicine 2000;3(1):1-10. [doi: 10.1080/10273660008833060]

\section{Abbreviations}

BG: blood glucose

BMI: body mass index

DM: diabetes mellitus

eA $\mathbf{1 c}_{1 \mathrm{c}}$ : estimated $\mathrm{A}_{1 \mathrm{c}}$

HbA $_{1 \mathbf{c}}$ : glycated hemoglobin

HBGI: high blood glucose index

LBGI: low blood glucose index

mHealth: mobile health

SDA: SocialDiabetes app

T1DM: type 1 diabetes mellitus

T2DM: type 2 diabetes mellitus

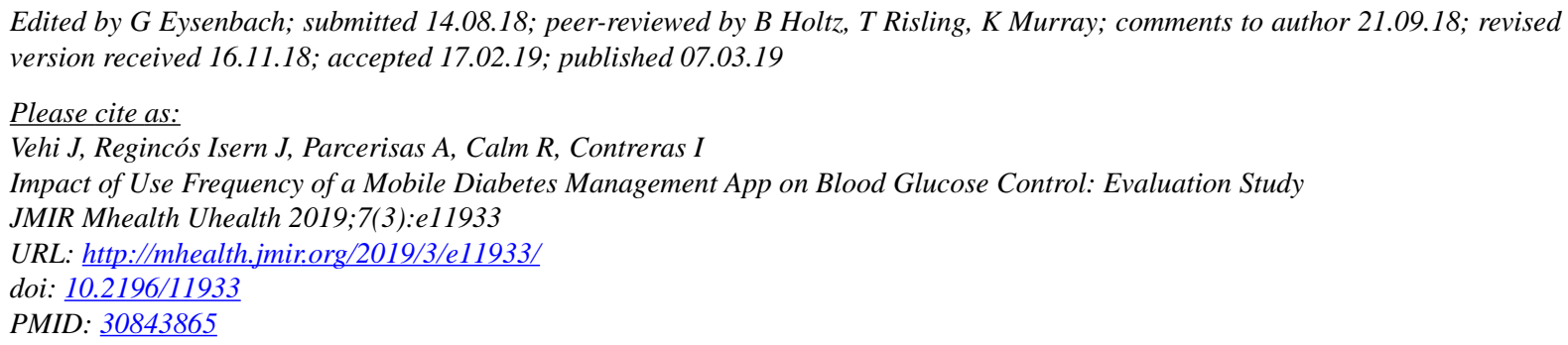

CJosep Vehi, Jordi Regincós Isern, Adrià Parcerisas, Remei Calm, Ivan Contreras. Originally published in JMIR Mhealth and Uhealth (http://mhealth.jmir.org), 07.03.2019. This is an open-access article distributed under the terms of the Creative Commons Attribution License (https://creativecommons.org/licenses/by/4.0/), which permits unrestricted use, distribution, and reproduction in any medium, provided the original work, first published in JMIR mhealth and uhealth, is properly cited. The complete bibliographic information, a link to the original publication on http://mhealth.jmir.org/, as well as this copyright and license information must be included. 